\title{
AVALIAÇÃO DA COMUNICABILIDADE DE UM SISTEMA DE DOAÇÃO DE LIVROS PARA BIBLIOTECAS PÚBLICAS
}

\section{COMMUNICABILITY EVALUATION OF A PUBLIC LIBRARY BOOK DONATION SYSTEM}

\author{
Mateus de Souza Monteiro', Bel. \\ Soraia Silva Prietch ${ }^{2}$, Dra. \\ (1) Universidade Federal de Mato Grosso, campus Rondonópolis (UFMT) \\ e-mail:mateuskalz@gmail.com \\ (2) Universidade Federal de Mato Grosso, campus Rondonópolis (UFMT) \\ e-mail: soraia.roo@gmail.com
}

Palavras-chave em português: Engenharia Semiótica, Pesquisa com usuários, Avaliação

A doação de livros é uma realidade, seja em instituições públicas ou privadas e, em sua maioria, o processo de doação é realizado por meio de um registro manual passível de extravio. Para que um Sistema de Doação de livros seja simples e eficaz, o uso do sistema deve ser claro e descomplicado. Diante disso, optou-se pela aplicação do Método de Inspeção Semiótica (MIS) e Método de Avaliação da Comunicabilidade (MAC), que possibilitaram a coleta de dados referente às falhas e rupturas na comunicação do Sistema de Doação de livros proposto neste artigo. Contudo, apesar do MAC ter contribuído com mais sugestões e ter apontado mais falhas, sua aplicação demanda mais estudo devido aos preparos que entrevistas necessitam e aos procedimentos de interpretação e marcação da reação dos usuários que fazem parte dos métodos da Engenharia Semiótica utilizados nesta pesquisa. Neste trabalho, os usuários contribuíram somente após o desenvolvimento, sendo que o sistema sofreu diversas alterações em função disso. De acordo com os resultados obtidos, evidencia-se claramente a necessidade da presença dos potenciais usuários nas diferentes etapas do ciclo de desenvolvimento de sistemas. Uma avaliação em fase de projeto poderia minimizar a quantidade de falhas no sistema em sua versão funcional.

Key-words in English: Semiotic Engineering, Users Research, Evaluation

The donation of books is a reality, in public or private institutions and, mostly, the process of donation is accomplished by a manual registration susceptible for loss. In order for a Book Donation System be simple and effective, its use must be clear and uncomplicated. Thus, it was decided the use of the Semiotic Inspection Method (SIM) and the Communicability Evaluation Method (CEM), which made possible the data collection on communication failures and ruptures of the Book Donation System proposed in this paper. However, although the use of CEM contributed with more suggestions and pointed to more failures, its use its use demands more study due to preparation that interviews requires, concerning with interpretation and tagging of users reactions that are part of the Semiotic Engineering used in this research. In this paper, the users contributed only after the development, so the system suffered several changes because of this. According with the results obtained, it was clearly highlighted the need of the presence of potential users in the different steps of systems development lifecycle. An evaluation in 


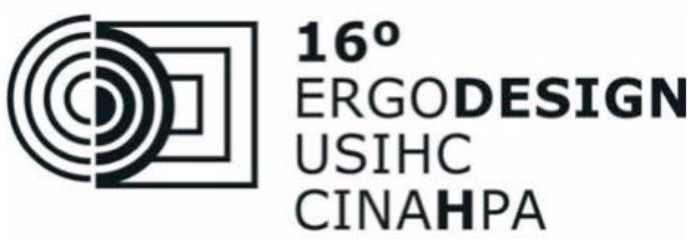

$16^{\circ}$ Ergodesign - Congresso Internacional de Ergonomia e Usabilidade de Interfaces Humano Tecnológica: Produto, Informações Ambientes Construídos e Transporte

$16^{\circ}$ USIHC - Congresso Internacional de Ergonomia e Usabilidade de Interfaces Humano Computador

CINAHPA | 2017 - Congresso Internacional de Ambientes Hipermídia para Aprendizagem.

the project phase could minimize the amount of failures on the system in its functional version.

\section{Introdução}

O Sistema avaliado neste trabalho, teve seu desenvolvimento iniciado durante a disciplina de Programação em Ambiente Web II em um curso de graduação de Sistemas de Informação. $\mathrm{Na}$ ocasião, a disciplina não incluía o uso de conceitos de Interface Humano-Computador (IHC); nesse aspecto, o sistema foi desenvolvido sem o amparo e a previsão de sua comunicabilidade e interação.

A motivação de se propor esse tipo de sistema foi que o processo atual de doação de livros da Biblioteca da Instituição de Ensino Superior (IES) ocorre de forma manual e, até certo ponto, de maneira simples. Em função disto, o manuseio do sistema deve ser claro e descomplicado a ponto de não diminuir o desinteresse do usuário com o sistema. Pois, caso ocorra, o usuário pode voltar a utilizar o método manual atual. $\mathrm{O}$ fato do processo de doação ser manual também é ruim para os clientes (gestores da Biblioteca), pois, devido a quantidade de atividades a serem realizadas não é possível, atualmente, manter um registro dos dados e gerar relatórios para conhecer padrões de doações e os perfis dos doadores, ou para fornecer feedback aos doadores sobre suas doações.

Além disso, esse tipo de sistema deve levar em conta a variedade dos perfis de potenciais usuários. Diante disso, considerou-se necessário voltar um passo atrás no ciclo de projeto, de modo que diversas lacunas fossem preenchidas com conhecimento relevante para a consolidação da aplicação. Nesse sentido, decidiu-se seguir o caminho apontado por Pressman et al. (2016), o qual afirma que quanto mais a equipe entender como os usuários interagem com o sistema, mais a equipe estará capacitada a caracterizar de maneira apropriada os requisitos e a construir modelos de análise e projetos proveitosos.
Nesse contexto, este artigo tem como principal objetivo avaliar a comunicabilidade do sistema de doação por meio de avaliações com usuários da biblioteca e doadores em potencial, bem como avaliar o sistema de doação em busca de rupturas e falhas de comunicação. Conforme o resultado dessas avaliações, validar e/ou promover melhorias no sistema.

As seções posteriores abordam, respectivamente, sobre os métodos utilizados, a elaboração do Mapa de Experiência da Jornada do Usuário, e os resultados da aplicação do MIS, do MAC e, por fim, as considerações finais.

\section{Abordagem sobre os métodos utilizados}

Optou-se pela utilização do Mapa de Experiência da Jornada do Usuário ( $u X$ Journey Map) para propiciar a visualização da experiência vivenciada pelo usuário referente à doação de livros. A história é detalhada de uma maneira acessível as interações e explicita emoções provocadas nos usuários em decorrência destas interações.

Em relação a representação dos usuários que interagem neste mapa, o Mapa da Jornada de Experiência do Usuário, utiliza o conceito de Personas. Conforme Raposo (2014), "Uma persona é um personagem fictício, modelo hipotético de um grupo de usuários reais, criado para descrever um usuário típico".

Além disso, quando iniciada a etapa de estudo preliminar, as informações apresentadas nas Personas, propiciam visualização geral dos utilizadores do sistema. É possível também utilizar estas informações para desenvolver funções (features) que atendam especificamente às necessidades dos usuários finais, bem como projetar a experiência do usuário de acordo com suas características. 


\section{$16^{\circ}$ ERGODESIGN USIHC CINAHPA}

Em função do problema abordado no artigo, foram escolhidos métodos de avaliação fundamentadas na área de estudos de signos e linguagens (BARANAUSKAS e ROCHA, 2003), a Engenharia Semiótica (EngSem).

Segundo Prates et al. (2006), os métodos de avaliação da EngSem proveem ferramentas para facilitar a interpretação do avaliador e para avaliar a qualidade de metacomunicação sobre as mais diversas instâncias da interação humanocomputador. Os métodos de avaliação da comunicabilidade, MIS e MAC, escolhidos para uso neste trabalho são fundamentados na EngSem.

Em relação ao MIS, esse método deve ser executado por um especialista, o qual examina uma diversidade de sinais os quais os usuários são expostos ao interagir com artefatos computacionais (PRATES, 2006). Na maioria dos casos, a aplicação do MIS se divide em 4 ou mais passos: a inspeção de sinais estáticos; a inspeção de sinais dinâmicos; inspeção dos sinais meta comunicacionais; a conclusão; e a construção da mensagem do designer para o usuário.

No que se refere ao MAC, Oliveira (2010) o descreve como um método de investigação, que envolve a participação de usuários em um ambiente controlado. Diferente do MIS, o MAC envolve a observação e a gravação da interação de como os usuários interagem com o sistema (MATTOS, 2010). O objetivo do método é identificar e antecipar algumas potenciais consequências de determinadas escolhas de projeto, por meio de interpretação do avaliador sobre experiência real dos usuários (MATTOS, 2010).

\section{Resultados da aplicação do Mapa de Experiência da Jornada do Usuário}

Em relação a representação dos usuários que interagem neste mapa, o Mapa da Jornada de $16^{\circ}$ Ergodesign - Congresso Internacional de Ergonomia e Usabilidade de Interfaces Humano Tecnológica: Produto, Informações Ambientes Construídos e Transporte

$16^{\circ}$ USIHC - Congresso Internacional de Ergonomia e Usabilidade de Interfaces Humano Computador

CINAHPA | 2017 - Congresso Internacional de Ambientes Hipermídia para Aprendizagem.
Experiência do Usuário, utiliza o conceito de Personas. Neste trabalho, as criações das Personas foram divididas em duas fases: aplicação sob a visão de um projetista e outra aplicação mediante entrevista com a gerente da Biblioteca da IES.

As Personas criadas sob o ponto de vista do projetista, apresentaram um perfil mais abrangente, tentando atender aos perfis que estivessem dentro do contexto onde a Biblioteca do Câmpus de Rondonópolis está inserida. Como por exemplo: alunos, ex-estudantes e professores em atividade.

Em relação às Personas criadas posterior a entrevista, foi possível identificar diferenças nos arquétipos levantados nas duas fases. Segundo a gerente da Biblioteca, os perfis dos doadores mais recentes estavam relacionados a professores aposentados da rede estadual com livros escolares, professores em atividade com livros de autoria própria e que gostariam de disponibilizar cópias e professores em atividades que lecionam e possuem livros desatualizados da época da graduação.

O Mapa da Jornada de Experiência do Usuário utilizado neste trabalho é inspirado em um modelo já existente, todavia, foram mantidos somente os campos Ponto de Contato e a Experiência Emocional. Estes campos são responsáveis por ilustrar o ponto em que o usuário (Persona) interage de alguma forma com o sistema e a emoção sentida pelo usuário em cada interação com o sistema.

\section{Resultados da aplicação do MIS}

A aplicação do MIS, dividiu-se em dois cenários. Os quais cenários foram:

- Cenário do doador - A Persona Diego gostaria de disponibilizar alguns exemplares dos seus livros autorais para a biblioteca da instituição. Recentemente ficou sabendo, em conversa com outros professores, do Sistema de Doação. Em casa, utilizando o notebook, 


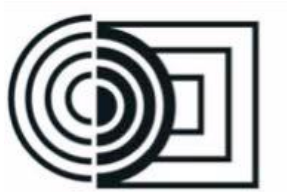

preencheu os dados dos dois livros no formulário e enviou para a biblioteca da instituição onde leciona.

- Cenário da bibliotecária - A Persona Rosana trabalha como coordenadora da biblioteca da instituição há quase três anos. Agora com o Sistema de Doação no ar, Rosana finalmente pode avaliar no computador da biblioteca os pedidos de doações dos livros antes de serem levados à biblioteca.

Uma das rupturas encontradas, é representada na Figura 1, na qual a frase "quantidade destes livros" do placeholder no formulário pode gerar uma confusão ao usuário do sistema, uma vez que a construção denota que possa ou tenha que haver mais de um livro para concluir o pedido de doação.

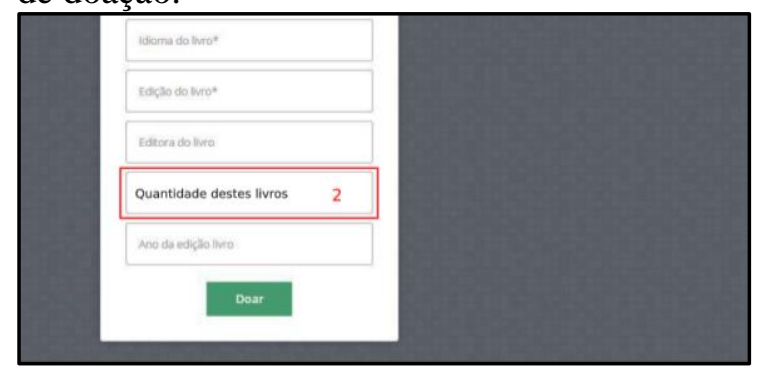

Figura 1 - Formulário de doação

No primeiro cenário, para o qual não é necessário realizar login para executar as tarefas, a busca por rupturas do sistema, encontrou falhas na barra de navegação, no formulário de doação e em alguns signos e mensagens de apoio. A partir das análises realizadas, dos signos metalinguísticos, estáticos e dinâmicos presentes na interface do Sistema de Doação, foi possível reconstruir a seguinte meta-mensagem consolidada:

- (Quem é você, usuário?) Eu acredito que você seja um usuário da internet e que deseja realizar a doação de um ou mais livros. Acredito que você prefere verificar se o(s) livro(s) que deseja doar estão aptos a compor o acervo antes de levá-los à biblioteca. $16^{\circ}$ Ergodesign - Congresso Internacional de Ergonomia e Usabilidade de Interfaces Humano Tecnológica: Produto, Informações Ambientes Construídos e Transporte

$16^{\circ}$ USIHC - Congresso Internacional de Ergonomia e Usabilidade de Interfaces Humano Computador

CINAHPA | 2017 - Congresso Internacional de Ambientes Hipermídia para Aprendizagem.

- (O que precisa fazer?) Para poder realizar a doação, você precisa preencher um formulário contendo informações pessoais e do livro. Os campos do formulário que disponibilizei para você são: Campos Pessoais (nome, e-mail, em qual Câmpus universitário a biblioteca se localiza) e Informações sobre o livro (Título do livro, Autor do livro, Idioma do livro, Edição do livro, Editora do livro, Quantidade dos livros e o ano da Edição do livro).

- (De que maneira prefere fazê-la (fazer a doação) e por quê?) Você prefere que o formulário não possua muitos campos, pois não quer que este processo seja cansativo. Você também quer saber o resultado da avaliação do bibliotecário de uma maneira descomplicada. Por esse motivo a resposta do pedido de doação vai para o seu e-mail, tendo em vista que estás habituado com a utilização desta ferramenta.

No segundo cenário, é necessário realizar o login antes de acessar a Dashboard do usuário bibliotecário. Ao acessar com as credenciais corretas, o bibliotecário entra no Painel de Controle do Usuário, e depara-se com uma tela que apresenta as informações sobre o pedido de doação recente.

Após a verificação realizada pelo Bibliotecário, independente da ação realizada (Aceitar ou Negar) é apresentado uma mensagem de confirmação da ação. Porém ao recusar o pedido, não é apresentado um campo que possibilite ao usuário bibliotecário colocar os motivos da recusa, tendo em vista que estes motivos podem ser específicos e, até em alguns casos, a solução pode ser resolvida com um novo envio de formulário.

Uma das principais rupturas encontradas é que, ao confirmar a ação, o processo de envio do email é iniciado, e não é apresentado feedback informando que o processo está em andamento e nem quanto tempo isso pode levar. Além disso, 


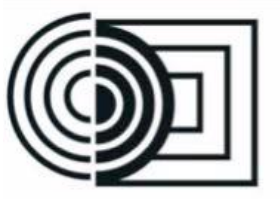

não existe uma mensagem de confirmação quando o usuário se desconecta do sistema.

A partir das análises realizadas, dos signos metalinguísticos, estáticos e dinâmicos presentes na interface do Sistema de Doação, referente ao usuário bibliotecário, foi possível reconstruir a seguinte meta-mensagem consolidada:

- (Quem é você, usuário?) Eu acredito que você seja um usuário da internet (já que o sistema é web). Deseja melhorar a forma como é realizada a doação de livros para a biblioteca e controlar da melhor maneira a qualidade dos livros que compõem e irão compor o acervo.

- (O que precisa fazer?) Para realizar o controle dos pedidos de doação é preciso que você esteja atento (a) aos pedidos recentes que são disponibilizados na página inicial da dashboard. Conforme os dados enviados no formulário e as políticas de doação da biblioteca, você deverá se orientar pelos critérios pré-definidos para aceitar ou recusar aquele pedido.

- (De que maneira prefere fazê-la (fazer a doação) e por quê?) Você não quer que este processo seja tão trabalhoso como é atualmente, por isso disponibilizei as informações da maneira mais visivel para você analisar cada pedido por vez. Como sei que às vezes você pode clicar, de forma não intencional, no botão "Confirmar" ou "Negar", coloquei uma mensagem de confirmação para você ter certeza se é realmente a sua intenção. Coloquei uma mensagem padrão para aceitar ou negar o pedido de doação, tendo em vista que o processo de análise dos pedidos é cansativo para você. Ao realizar o logoff sei que essa possivelmente é sua real intenção.

A partir da aplicação do Método de Inspeção Semiótica (MIS), considerando ambos os cenários descritos anteriormente, pôde-se constatar que o designer do sistema demonstrou uma certa preocupação ao confirmar a intenção do usuário em aceitar/negar. Contudo, existe a $16^{\circ}$ Ergodesign - Congresso Internacional de Ergonomia e Usabilidade de Interfaces Humano Tecnológica: Produto, Informações Ambientes Construídos e Transporte

$16^{\circ}$ USIHC - Congresso Internacional de Ergonomia e Usabilidade de Interfaces Humano Computador

CINAHPA | 2017 - Congresso Internacional de Ambientes Hipermídia para Aprendizagem. falta alguns signos estáticos e dinâmicos que possibilite a acessibilidade. Dentre os pontos negativos levantados, destacam-se:

- A falta de explicação em relação ao elemento "Entrar" na barra de navegação no topo da página, pois não é necessário entrar para realizar o pedido de doação e o login é restrito aos bibliotecários;

- A falta de textos de aviso explicativos e de auxílio ao usuário sobre como preencher o formulário de forma correta;

- A falta da informação sobre a política de Doação da biblioteca do Câmpus, tendo em vista que a política de doação é um critério crucial em relação a avaliação do pedido;

- A falta de um feedback visual quando o usuário bibliotecário confirmar a avaliação do pedido de doação;

- A falta de acessibilidade.

\section{Resultados da aplicação do MAC}

Por se tratar de um sistema em que onde o perfil dos usuários é bem diverso, não foi necessário a aplicação de um questionário de seleção dos participantes.

Contudo, foi dada a preferência aos participantes que estivessem habituados ao cotidiano da universidade.

Para orientar a execução das avaliações (piloto e efetiva), foi criado um roteiro. Como primeiro passo do roteiro, convidar os participantes para a avaliação. Caso o participante aceitasse, convidá-lo ao laboratório de informática ou pesquisa onde seria realizado a avaliação.

Posteriormente, explicar o termo de consentimento de participação voluntária na avaliação. $\mathrm{O}$ termo de consentimento descreve a pesquisa e seus objetivos principais, além das diretrizes éticas para sua realização. Depois de lido o termo, cada participante teve a liberdade de decidir se continuaria ou não a participar do teste. Prosseguindo para a aplicação do 


\section{$16^{\circ}$ ERGODESIGN USIHC CINAHPA}

questionário de perfil, a realização da avaliação e o questionário de avaliação.

Para o usuário, foi passado somente uma tarefa em ambas as avaliações (piloto e efetiva), a qual era: Realizar dois pedidos de doação no sistema, de forma que os dados do livro fossem diferentes de cada pedido. Os questionários utilizados nas avaliações, foram criados na plataforma do Google Docs e a captura das reações dos participantes e a interação do mesmo com o sistema foi realizado com o software ScreenCastify.

\subsection{Avaliação Piloto}

Nesta avaliação, procura-se observar se os participantes conseguem entender corretamente o material apresentado, se o tempo de execução está dentro do previsto, se é viável, se através das tarefas propostas consegue-se obter as medidas especificadas e se precisa ser realizado algum ajuste no questionário e/ou forma de atuação do mediador, de modo que na avaliação efetiva a mesma possa transcorrer como desejado.

Assim como dito anteriormente, não foram realizados pré-testes para seleção dos participantes, apenas que estivessem habituados com o cotidiano na IES. O convite foi feito pessoalmente no dia da aplicação das avaliações. O número total de participantes na fase piloto foi de 5 pessoas. Sendo dentre as 5 pessoas, 3 do sexo feminino e 2 do masculino. Quanto ao curso de graduação dos participantes, 2 de Sistemas de Informação, 1 da Ciência da Computação, 1 de Arquitetura e Urbanismo e 1 de Direito.

Apenas alguns problemas técnicos aconteceram durante a realização das avaliações e estavam relacionados a conexão. Antes do início da tarefa, fora pedido aos participantes que aguardassem a inicialização do software que realiza a gravação da interação. Na Figura 2 consta um exemplo da tela para mostrar, de $16^{\circ}$ Ergodesign - Congresso Internacional de Ergonomia e Usabilidade de Interfaces Humano Tecnológica: Produto, Informações Ambientes Construídos e Transporte

$16^{\circ}$ USIHC - Congresso Internacional de Ergonomia e Usabilidade de Interfaces Humano Computador

CINAHPA | 2017 - Congresso Internacional de Ambientes Hipermídia para Aprendizagem.

forma estática, como o vídeo da interação é gravado.

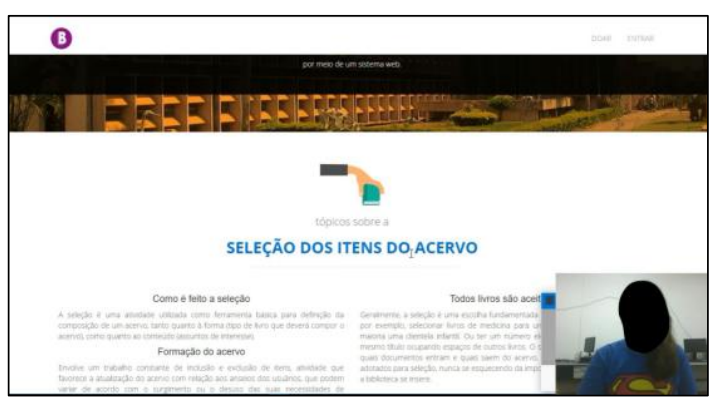

Figura 2 - Captura de tela da avaliação

No geral, os participantes não tiveram dificuldades para execução da tarefa, tendo em vista que dentre os cinco participantes apenas 1 não obteve sucesso ao concluir a tarefa. Além disso, em nenhum caso foi requisitado algum recurso de acessibilidade e nem foram procurados recursos de ajuda no sistema.

No que se diz respeito ao tempo total da avaliação (iniciando com a explicação do termo de consentimento e finalizando com o agradecimento pela participação) o maior tempo fora de 19 minutos e o menor de 9 minutos. Os participantes fizeram comentários sobre $o$ funcionamento do sistema, condução da avaliação e sobre as mensagens de confirmação.

Durante a avaliação piloto, notou-se algumas falhas no processo de avaliação que poderiam atrapalhar durante a realização de marcação realizada posteriormente a fase de análise dos resultados. Uma delas é que, no momento de realizar a doação, os usuários levam um tempo para lembrar os dados do livro ou gerar algum dado fictício, durante a realização da tarefa (preenchimento dos formulários no sistema).

Notou-se a necessidade de deixar exposto ao usuário qual a tarefa a ser realizada e o roteiro para norteio do avaliador durante a execução da tarefa.

\subsection{Avaliação Efetiva}

Realização:
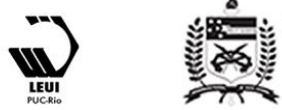


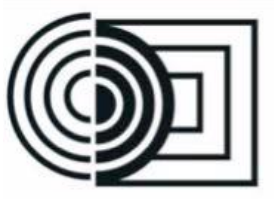

Após a realização do teste piloto e levantados os pontos que necessitavam de mudanças, estes foram considerados e aplicados. Entretanto, por mais que o livro facilitasse ao doador que não precisasse gerar ou lembrar das informações, os usuários gastaram quase o mesmo tempo para procurar as informações (edição, ano da edição, editora, dentre outras) nos livros. A diferença no tempo médio de execução da tarefa entre a efetiva e o piloto foi de apenas 0,10 segundos.

O critério de seleção do perfil dos participantes da avaliação efetiva, seguiu o mesmo princípio da aplicada no piloto. Assim como também o convite fora feito pessoalmente na IES. O número total de participantes foi 13 .

Dentre os motivos principais dos usuários que realizaram as doações para a biblioteca, estavam: "Desocupar espaço" e "Desfazer de materiais pessoais". Sendo a experiência da doação classificada pelos participantes como "Positiva" e "Indiferente".

No geral, as avaliações ocorreram sem problemas técnicos, salvo quando ocorreram quedas na conexão do laboratório onde foram realizadas as entrevistas. É interessante notar que, a proporção de usuário que tiveram dificuldades para concluir ou não realizarem a tarefa é alta em relação aos que conseguiram concluir sem problemas. A diferença é de até $30 \%$ e, novamente, parte desta taxa está diretamente relacionada às rupturas de comunicação que o sistema possuía. Porém, no questionário de avaliação respondido pelos participantes, 92,3\% afirma que concluiu sem nenhuma dificuldade o pedido de doação.

\subsection{Sugestão dos participantes}

As sugestões nas avaliações (piloto e efetiva) feitas pelos participantes, foram:

- Incremento do campo: estado dos livros (conservação, rasuras, páginas faltando, dentre outros), volume, condição;

- Retorno da tela para o campo com o erro; $16^{\circ}$ Ergodesign - Congresso Internacional de Ergonomia e Usabilidade de Interfaces Humano Tecnológica: Produto, Informações Ambientes Construídos e Transporte

$16^{\circ}$ USIHC - Congresso Internacional de Ergonomia e Usabilidade de Interfaces Humano Computador

CINAHPA | 2017 - Congresso Internacional de Ambientes Hipermídia para Aprendizagem.
- Ao finalizar o pedido, não retornar para a tela do formulário;

- Incluir opções de respostas abertas, visto que alguns livros não possuem edição, editora, ano, dentre outras;

- Feedback na conclusão do pedido de doação;

- Possibilitar o cadastro para doadores, uma vez que a doação possa ocorrer com uma certa frequência;

- Possuir um campo de ajuda sobre como preencher os campos dos formulários.

É relevante ressaltar que dentre as sugestões realizadas pelos participantes das avaliações, apenas a mensagem de sucesso no envio do pedido de doação e as seções iniciais se assemelham aos pontos levantados no MIS.

\subsection{Etiquetagem}

Na etapa de Etiquetagem, após a captura das interações durante as avaliações, a execução é analisada por um especialista e associadas as expressões feitas pelos usuários etiquetas ao tipo de ruptura de comunicação entre o usuário e o sistema identificado (MATTOS, 2010). Na Tabela 1 são apresentados os tipos e as quantidades de rupturas verificadas durante a avaliação efetiva e a avaliação piloto. As marcações: Não obrigado; e Socorro; não apresentaram nenhuma marcação tanto na avaliação Efetiva quanto na Piloto e, por esse motivo, não são apresentadas na tabela.

\begin{tabular}{|c|c|c|}
\hline \multirow{2}{*}{$\begin{array}{c}\text { Expressões de } \\
\text { comunicabilidade }\end{array}$} & Av. Piloto & Av. Efetiva \\
\cline { 2 - 3 } & 5 usuários & 13 usuários \\
\hline Cadê? & 1 & 2 \\
\hline E agora? & 2 & 3 \\
\hline Onde estou & 2 & 1 \\
\hline Por que não funciona? & 2 & 2 \\
\hline Ué, o que houve? & 2 & 9 \\
\hline Para mim está bom & 2 & 9 \\
\hline O que é isto? & 0 & 2 \\
\hline Epa & 0 & 1 \\
\hline Assim não dá & 0 & 1 \\
\hline Vai de outro jeito & 0 & 1 \\
\hline
\end{tabular}

Realização:
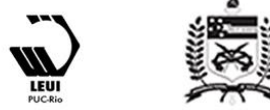


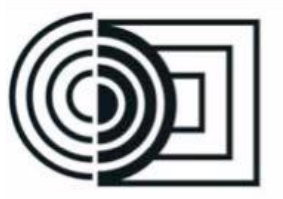

Tabela 1 - Etiquetagem das avaliações piloto e efetiva

A Figura 3 apresenta um dos usuários da avaliação efetiva perdido após obter um resultado inesperado do sistema ao executar uma ação. Isso pode ser identificado pela forma que o usuário reage ao resultado da ação e a forma como desliza o cursor na tela sem um objetivo definido, sendo representado pelo traço amarelo na imagem.

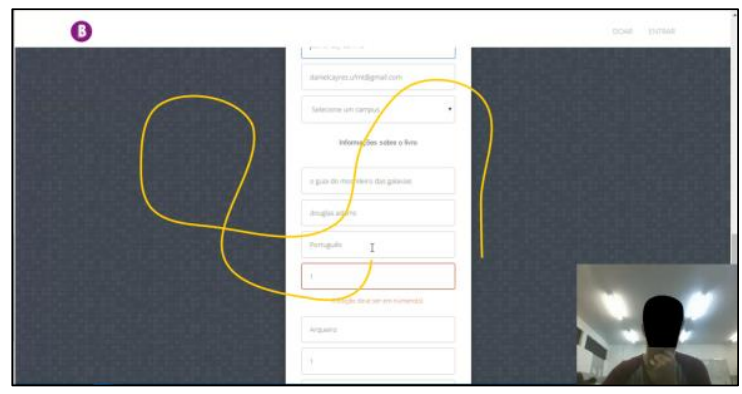

Figura 3 - Participante da avaliação apresentando um padrão da tag "Ué, o que houve?"

O traço amarelo representado na Figura 3 foi desenhado sobre a captura de tela, representando o movimento do cursor de forma manual (usando a ferramenta XY) sem o auxílio de ferramenta de rastreamento do olhar ou do mouse (eye-tracking ou mouse-tracking).

\subsection{Perfil Semiótico}

Neste ponto, após a aplicação das avaliações, é gerado um perfil semiótico que consiste em um diagnóstico aprofundado do processo de metacomunicação entre projetista e usuário (MATTOS, 2010). Realizado como se o projetista dissesse ao usuário, através do sistema:

Caro usuário, o sistema de doação de livros é uma ferramenta que eu criei para você, que precisa realizar doações para bibliotecas. $O$ sistema de doações, além de permitir o envio do pedido de doação, também tem a função de ajudá-lo na compreensão da composição do $16^{\circ}$ Ergodesign - Congresso Internacional de Ergonomia e Usabilidade de Interfaces Humano Tecnológica: Produto, Informações Ambientes Construídos e Transporte

$16^{\circ}$ USIHC - Congresso Internacional de Ergonomia e Usabilidade de Interfaces Humano Computador

CINAHPA | 2017 - Congresso Internacional de Ambientes Hipermídia para Aprendizagem. acervo da biblioteca. É recomendado que você confira os dados antes do envio do formulário, pois mesmo que possua um controle dos dados, em algum caso pode passar algo despercebido e não apresento nenhuma mensagem para confirmar a execução do pedido. Eu também recomendo que no envio errado do formulário, não clique no botão doar no topo da página, pois isso atualiza a página e perde os dados anteriores do formulário.

Após realizar as interpretações posteriores ao Método de Inspeção Semiótica (MIS) e o Método de Avaliação da Comunicabilidade (MAC), foi possível levantar os seguintes pontos: melhorias de comunicabilidade; melhorias na base de dados; melhorias na interface; melhorias na funcionalidade do sistema e melhorias na organização dos elementos na interface do sistema;

Contudo, devido à grande quantidade de sugestões e melhorias identificadas, fez-se necessário a princípio a seleção de algumas melhorias para implementação inicial, as quais foram:

- Colocar aviso aos usuários doadores sobre a não necessidade de realizar login para envio do formulário de doação;

- Adicionar botão para aumentar e outro botão para diminuir o tamanho da fonte do formulário;

- Alterar placeholder dos campos dos formulários com exemplos de preenchimento dos campos;

- Adicionar campos: estado de conservação do livro (conservação, rasuras, páginas faltando, dentre outros) e volume;

- Nos campos volume e edição, deixar claro para os usuários que eles devem preencher somente números;

- Alterar cores das páginas adicionando mais contraste;

- Melhorar as seções informativas sobre: a doação e composição do acervo;

- Após o envio do formulário, apresentar ao usuário quais foram as informações inseridas no formulário e então confirmar o pedido; 


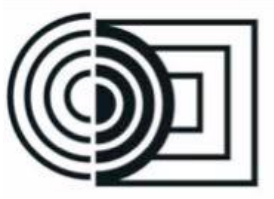

- Alterar mensagem de sucesso;

- Notificar a existência de erro e melhorar as mensagens de tratamento do formulário.

\section{Considerações Finais}

Os objetivos propostos para este trabalho foram atingidos. A elaboração do Mapa de Experiência da Jornada do Usuário foi de grande valia, uma vez que entender o comportamento dos usuários possibilitou mudanças na interface e a criação de novas funcionalidades para o sistema.

A aplicação dos métodos de avaliação da EngSem gerou uma série de registros de rupturas e falhas na comunicação do sistema, sejam elas identificadas por especialista ou por participantes das avaliações, devido ao seu nível de detalhamento na coleta dos dados e aos protocolos para a condução da investigação.

Dentre os métodos utilizadas para aplicação neste trabalho, a aplicação do MAC destacou-se pela quantidade de sugestões levantadas pelos participantes, durante a avaliação, e durante a fase de etiquetagem e interpretação das gravações.

Contudo, a fase de preparação do MAC, demanda mais estudo e preparo que a aplicação do MIS, que por sua vez não necessita de participação de terceiros, nem depende de algum local específico para ser realizado.

Além disso, a quantidade de requisitos gerados para a fase de melhoramento do sistema foi maior do que esperava-se, demandando uma filtragem e seleção dos requisitos (funcionais e não funcionais) que necessitavam mais urgência para serem atendidos. Os critérios de seleção partiram da onde mais os usuários tiveram dificuldades na execução das tarefas.

Por fim, a perspectiva é de continuidade do trabalho, sendo o próximo passo previsto: a realização do MAC sob o ponto de vista da(o) bibliotecária(o). Posteriormente, as melhorias e, $16^{\circ}$ Ergodesign - Congresso Internacional de Ergonomia e Usabilidade de Interfaces Humano Tecnológica: Produto, Informações Ambientes Construídos e Transporte

$16^{\circ}$ USIHC - Congresso Internacional de Ergonomia e Usabilidade de Interfaces Humano Computador

CINAHPA | 2017 - Congresso Internacional de Ambientes Hipermídia para Aprendizagem.

por fim, o encaminhamento de relatório técnico com solicitação de implantação do sistema na biblioteca da IES.

\section{BIBLIOGRAFIA}

CYBIS, W. A; BETIOL, A. H.; FAUST, R. Ergonomia e Usabilidade: conhecimentos, métodos e aplicações. 1. ed. Novatec, 2010. 344 p.

\section{MATTOS, B. A. M. Uma extensão do método de avaliação de comunicabilidade para sistemas colaborativos. 2010. $170 \mathrm{fls}$. Dissertação (Mestrado em Ciência da Computação) - Universidade Federal de Minas Gerais, 2010.}

\section{OLIVEIRA, R. O. Investigação sobre a} aplicabilidade dos métodos de avaliação da comunicabilidade ao domínio educacional. 2010. 226 fls. Dissertação (Mestrado em Ciência da Computação) - Universidade Federal de Minas Gerais. (2010).

PRATES, R. O; Silva, E. J; Leitão, C. F; Souza, C. S. The Semiotic Inspection Method. Natal, Anais do IHC, 2006.

PRESSMAN R. S; MAXIM B. R. Engenharia de Software: uma abordagem profissional. AMGH Editora Ltda. $8^{a}$ edição. ISBN 978-007-802212- 8, 2016.

RAPOSO, A. B. Design de IHC: Organização do Espaço de Problema: INF1403 - Introdução a IHC. Slides de aula, SERG, PUC Rio, 2014. Disponível em: goo.gl/sUQ9Q0, acesso dia 12/09/2016.

REIS, S. S. Avaliação do Método de Inspeção Semiótica. 2012. 246 fls. Dissertação (Mestrado em Ciência da Computação) - Universidade Federal de Minas Gerais. 2012. 
$16^{\circ}$ USIHC - Congresso Internacional de Ergonomia e Usabilidade de Interfaces Humano Computador

CINAHPA | 2017 - Congresso Internacional de Ambientes Hipermídia para Aprendizagem.

ROCHA, H. V; BARANAUSKAS, Maria

Cecília Calani. Design e Avaliação de

Interfaces Humano-Computador. Campinas:

Unicamp, 2003. 